\title{
Modelling undesirable outputs with zero sum gains data envelopment analysis models
}

\author{
EG Gomes ${ }^{1}$ and MPE Lins ${ }^{2 *}$ \\ ${ }^{1}$ Brazilian Agricultural Research Corporation (Embrapa)_Secretariat for Management and Strategy, \\ Brasília, DF, Brazil; and ${ }^{2}$ Federal University of Rio de Janeiro - Production Engineering Program, \\ Rio de Janeiro, RJ, Brazil
}

Data envelopment analysis (DEA) literature has proposed alternative models for performance assessment in the presence of undesirable outputs, such as pollutant emissions, where increased outputs imply reduced performance. However, the case where global equilibrium of outputs should be imposed has not yet been considered. We propose that the zero sum gains DEA (ZSG-DEA) models look especially suitable for treating equilibrium models, where the sum of the quantities produced by all decision-making units can be set as the upper admissible bound. This paper uses ZSG-DEA models to evaluate the carbon dioxide emission case study, which can be considered part of the Kyoto Protocol statement.

Journal of the Operational Research Society advance online publication, 7 February 2007 doi:10.1057/palgrave.jors.2602384

Keywords: data envelopment analysis; zero sum gains; undesirable outputs

\section{Introduction}

An undesirable output is an undesirable result of a productive process, whose production must be minimized. Scheel (2001) presents an updated discussion about data envelopment analysis (DEA) models that involve undesirable outputs, with an emphasis on the economic-environmental context analysis.

Dyckhoff and Allen (2001) characterize three main approaches to modelling undesirable outputs in a DEA context, whose choice is frequently made in an arbitrary way. The same authors discuss the advantages and disadvantages of these approaches.

The first one uses the reciprocal of the undesirable output as DEA output, that is, the undesirable output is modelled as being desirable $\left(f\left(u_{i}^{k}\right)=1 / u_{i}^{k}\right.$, where $u_{i}^{k}$ is one of the elements of the matrix $U$ of the undesirable outputs $i$ of the decisionmaking unit (DMU) $k$ ). This approach is applied, for example, by Lovell et al (1995) and called 'reciprocal multiplicative' (Golany and Roll, 1989; Scheel, 2001).

The second method (Rheinhard et al, 1999) considers DEA as a multi-criteria approach, that is the undesirable output is modelled in DEA as input. In this case, both CCR and BCC DEA models can be used, depending on the operational scale of the DMUs. As mentioned by Scheel (2001), when considering undesirable outputs as inputs, we are creating the same production possibility set as if we were considering the undesirable outputs as desirable by using the transformation $f(U)=-U$ (reciprocal additive transformation).

\footnotetext{
*Correspondence: MPE Lins, Rua Belisario Tavora 80 ap 506, Laranjeiras, Rio de Janeiro 22245-070, Brazil.

E-mail: estellita@pep.ufrj.br
}

The third approach is based on values translation (Ali and Seiford, 1990), adding to the reciprocal additive transformation of the undesirable output $i$ a positive scalar $\beta_{i}$, big enough, so that the final values are positive for each DMU $k\left(f\left(u_{i}^{k}\right)=-u_{i}^{k}+\beta_{i}\right)$. We stress, however, that this approach is only valid for BCC (Banker et al, 1984) and additive DEA models (Charnes et al, 1985), since CCR (Charnes et al, 1978) is not translation invariant (Cooper et al, 2000).

Färe et al (1996) and Färe and Grosskopf (2001) went further, proposing a new property for modelling undesirable outputs, which is the weak disposability hypothesis, that is assuming that the data can show evidence of a decreasing output level as the level of inputs increases. The environmental performance is measured by dividing two distance functions: one that includes and another that excludes the undesirable output.

Dyckhoff and Allen (2001) stress, however, that the approach must only be used when the decision maker is really sure about the technical relations between undesirable outputs and certain inputs and outputs.

The state of the art in DEA models in the presence of undesirable outputs can be seen in works by Färe et al (1989, 2000), Yaisawarng and Klein (1994), Lovell et al (1995), Färe and Grosskopf (1995, 2003, 2004), Thanassoulis (1995), Tyteca (1996), Rheinhard et al (1999, 2000), Scheel (2001), Hailu and Veeman (2001), Zofio and Prieto (2001), Dyckhoff and Allen (2001), Sun (2002), Seiford and Zhu (2002); Murtough et al (2002), Kumar and Khanna (2002), Korhonen and Luptacik (2003), and Gomes (2003).

DEA models described in the literature consider that the undesirable outputs can be reduced in an independent 
manner, without integration or cooperation among the production units. In this paper, we propose a new approach to modelling undesirable outputs, based on the zero sum gains DEA models (ZSG-DEA). These models consider the production dependence among the DMUs (Gomes, 2003; Gomes et al, 2003, 2005; Lins et al, 2003), including, as an additional restriction, the zero sum game property, in which whatever lost (or gained) by one of the players must be gained (or lost) by the others, that is the net sum of gains must be zero.

When assessing performance from a global perspective, it is necessary to include overall constraints across the undesirable output, as the sum of the produced quantities in all the units can be seen as the maximum allowed limit and cannot be surpassed. ZSG-DEA models can account for this property, especially to indicate management directions to the evaluated units. This means that any DMU that wants to reach the efficient frontier by increasing the output (or decreasing the input) will oblige the others to reduce (or increase) their values by this amount, in order not to change the total (net gains sum is equal to zero). This increase-reduce scenario causes the redistribution of these quantities, based on DEA efficiency score. In the case of pollutants, for instance, ZSG-DEA models can be useful for the ecological economy (Sachs, 2000) that provide limits or scales definition for pollutants emission and allocation improvements.

In DEA literature, there is no reference to undesirable output reallocation in order to keep the total sum unchanged or about pollutants trade. The case study presented in this paper contributes to this theme, as it uses ZSG-DEA models to propose a scenario regarding $\mathrm{CO}_{2}$ emissions trade, following the Kyoto Protocol flexible mechanisms.

\section{Zero sum gains DEA models}

Original DEA models (CCR, BCC and their variants) assume complete input (or output) independence, that is the input (or output) of any given DMU does not affect the input (or output) of the others. In some cases, however, this independence does not exist. In the case of competitions, for example, if one output is considered to be the resulting aggregate scores, the higher the position of any given competitor, the more he pushes down the positions of others (Lins et al, 2003).

Another example is in the efficiency evaluation of productive units that produce something to supply a constant demand. In this case, if an inefficient DMU increases its production and reaches the efficient frontier, other units will have to reduce their production, in order to keep the fixed amount determined by the demand.

These new models, named ZSG-DEA models, represent a situation similar to a zero sum game (Osborne and Rubinstein, 1999), where all that was gained (lost) by one of the players must be lost (gained) by the others, that is the net gains sum must equal zero. In opposition to what occurs to the original DEA models, the way one DMU reaches its target in the efficient frontier implies changing the frontier. Lins et al (2003) proposed strategies in DEA targets searching, with emphasis on the proportional reduction strategy. According to this strategy, the inefficient DMU searching for efficiency must lose some amount of input (or alternatively receive some quantity of output). In order to keep the total sum constant, the other DMUs must receive that amount of input (lose that quantity of output) proportionally to their original values of that input (output).

The formulation (1) represents the ZSG-DEA CCR model, input-oriented, for the case that just one DMU searches for the efficient frontier and with one constant sum input (Gomes, 2003; Gomes et al, 2005). In this model, $h_{R o}$ is the DMU $o$ efficiency under the restriction that the input sum must be constant; $x_{j}$ and $y_{j}$ are the inputs and outputs original values, respectively; $y_{o}$ and $x_{o}$ are the outputs and inputs for the DMU $o ; \lambda_{j}$ are DMU contributions to the efficient projection. ZSGDEA BCC is analogous, including the convexity restriction $\sum_{j} \lambda_{j}=1$ and can be found in Lins et al (2003).

$$
\begin{array}{ll}
\operatorname{Min} & h_{R o} \\
\text { s.t. } & \\
& h_{R o} x_{o} \geqslant \sum_{j} \lambda_{j} x_{j}\left[1+\frac{x_{o}\left(1-h_{R o}\right)}{\sum_{j \neq o} x_{j}}\right] \\
& \sum_{j} \lambda_{j} y_{j} \geqslant y_{o} \\
& \lambda_{j} \geqslant 0 \quad \forall j
\end{array}
$$

\subsection{Cooperation among DMUs}

The situation modelled in (1) represents the case in which a single DMU aims at the efficient frontier. There is the possibility, however, that more than one DMU will search, at the same time, for the sake of maximizing their efficiency, which can be done in competition or in cooperation. In this paper, we deal only with the cooperative case. According to the ZSG-DEA paradigm, the cooperation strategy implies that the DMUs belonging to the 'cooperation group' do try to take input amounts out only from the DMUs that are not in this group, as shown in Figure 1, in which DMUs A and B are in cooperation.

For the example illustrated in Figure 1, ZSG-DEA model is formulated as a non-linear bi-objective programming problem. In the general case, where several inefficient DMUs compose the 'cooperation group', ZSG-DEA model is a non-linear multi-objective programming problem. This kind of problem usually needs metaheuristics to be solved. For the proportional reduction strategy, however, this model can be reduced to a non-linear mono-objective programming problem, as proved by the Proportional Strategy Theorem (Gomes, 2003). This theorem states that, in the case where several DMUs act in cooperation to reach their targets in the efficient frontier using the proportional strategy, the efficiency of DMUs in the ZSG-DEA model is directly proportional to their efficiency in the corresponding classical DEA model. 


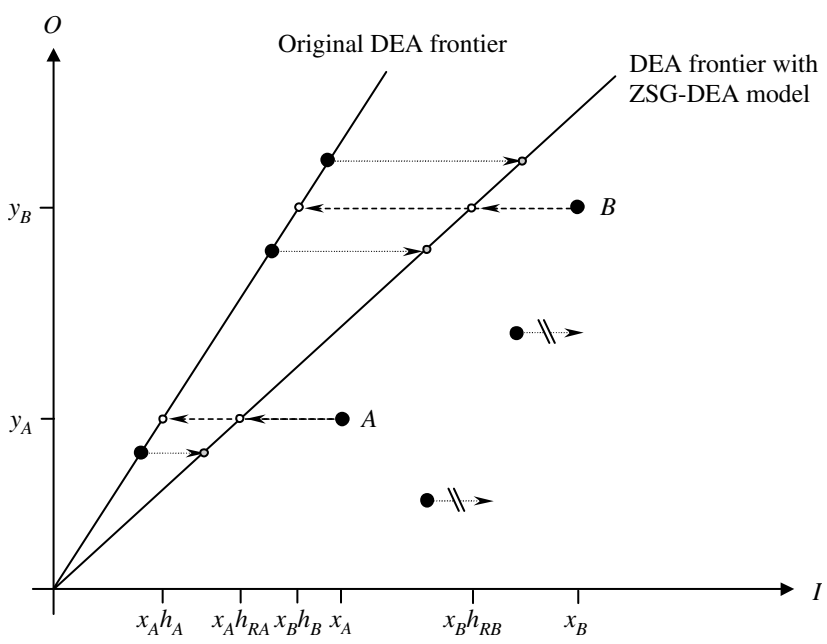

Figure 1 Search for efficiency in cooperation (ZSG-DEA CCR model).

Moreover, Lins et al (2003) show that 'the target of the DMU under consideration in the ZSG-DEA model with proportional reduction strategy is equal to the target in the corresponding classical DEA model multiplied by a reduction coefficient' (named by Gomes (2003) as 'Target's Assessment Theorem') and that 'in a ZSG-DEA model in which a proportional reduction strategy has been adopted, the value of the DMUs $j$ contribution $\lambda_{j}, j$ different from DMU under analysis, equals its value in the traditional DEA model' (named by Gomes (2003) as 'Benchmarks' Contribution Equality Theorem'). Using all these theorems jointly (Gomes 2003; Gomes et al, 2003, 2005) results in Equation (2), where $W$ is the cooperative DMUs set, $q_{i j}=h_{i} / h_{j}$ is the proportionality factor that comes from the proportional strategy and $h_{i}, h_{j}$ are the classical DEA efficiencies.

$$
h_{R i}=h_{i}\left(1+\frac{\sum_{j \in W}\left[y_{j}\left(1-q_{i j} h_{R i}\right)\right]}{\sum_{j \notin W} y_{j}}\right)
$$

Equation (3) is the equation that must be solved when modelling ZSG-DEA CCR and BCC models with output orientation.

$$
h_{R i}=h_{i}\left(1-\frac{\sum_{j \in W}\left[y_{j}\left(q_{i j} h_{R i}-1\right)\right]}{\sum_{j \notin W} y_{j}}\right)
$$

\subsection{Uniform DEA frontier}

If all inefficient DMUs comprise a single cooperation group and search for efficiency in the original DEA efficient frontier, ZSG-DEA model will promote the total redistribution/reallocation of the input (or output) with constant sum. After this reallocation, all the DMUs will belong to the efficient frontier, that is all DMUs will be $100 \%$ efficient.

This new DEA frontier, called here uniform DEA frontier or maximum efficiency DEA frontier, will be located at a lower level in relation to the original one, as the efficient DMUs must gain units of input (or lose some quantities of output) to compensate for the loss (or gain) of the inefficient DMUs, so that the sum is kept constant. This maximum efficiency redistributive strategy can be appropriate when a regulatory agent can induce the DMUs behaviour aiming at resources (or production) allocation where all DMUs would be $100 \%$ efficient.

Equation (2) represents the expression that 'builds' the uniform frontier in a direct way, with all inefficient DMUs taking part in the cooperative group $W$, considering the inputoriented DEA CCR model. This equation is valid for ZSGDEA CCR and BCC models, input-oriented. The proportional reduction strategy guarantees the validity of the theorems mentioned in Section 2.1, which avoids solving the resulting non-linear programming problem. The proofs can be found in Gomes (2003).

The issue of interpendence among DMUs when searching for targets is also treated by Lozano and Villa (2004) and Avellar et al (2006). However, ZSG-DEA models bring more interesting and simpler results, and treats both CCR and BCC models. Additionally, our approach neither imposes any functional form to the efficient frontier (as the one of Avellar et al (2006), which is valid only for CCR), nor needs the efficiency maximization of each DMU simultaneously to the minimization of total resources or maximization of total production (as the approach of Lozano and Villa (2004), valid for BCC model). Our model needs only the calculation of DEA scores followed by the solution of a single equation.

\section{Case study: $\mathrm{CO}_{2}$ emission redistribution}

\subsection{Historical background}

Human activities have altered the chemical composition of the atmosphere through the build-up of greenhouse gases - primarily carbon dioxide, methane, and nitrous oxide. Since the beginning of the industrial revolution, atmospheric concentrations of carbon dioxide have increased nearly $30 \%$, methane concentrations have more than doubled, and nitrous oxide concentrations have risen by about $15 \%$. Fossil fuels burned to run cars and trucks, heat homes and businesses, and power factories, are responsible for about $98 \%$ of US carbon dioxide emissions, $24 \%$ of methane emissions, and $18 \%$ of nitrous oxide emissions.

In December 1997, the Kyoto Protocol was established in order to achieve the objective of the United Nations Framework Convention on Climate Change, which proposes that greenhouse gases in the atmosphere must be set at concentrations that do not affect the life on Earth.

The main goal of the Kyoto Protocol for the 2008-2012 period is to persuade the industrialized countries (called Annex I parties) to reduce and control their greenhouse gases emissions by at least 5\% in relation to the 1990 levels. We argue about the adequacy of this criterion, as it does not consider the different characteristics of the countries when 
assessing environmental efficiency. It is common, when dealing with inter- and intra-governmental policies, to claim for status quo maintenance, accepting the present levels of production, consumption, or emission as references for new rules. A well-known example is the case of energy shortages followed by rationing, where the single quotas are usually established on the basis of past consumption (historical series) and do not take into account the domestic and industrial needs. These decisions are indeed far from socially fair.

As the Kyoto Protocol intends to control a global scale phenomenon, the key factor to be controlled is the global emission level. The individual country emissions can be flexible, though conditioned by a rigid global balance. So, the parties must either reduce their domestic emissions or use the socalled 'flexible mechanism' to fulfil their goals: Joint Implementation.

The Clean Development Mechanism allows for a carbon emission quota trade between low emission level (Non-Annex I) countries and the Annex I parties, with no change in the global emission level. According to the Clean Development Mechanism, the countries with high emission levels could keep their emission levels if they finance projects in the NonAnnex I countries, providing a compensatory reduction, in order to achieve the established limit. This is the so-called 'Carbon Market', whose goal is to decrease the economic impact in the Annex I parties and to make the Kyoto Protocol objectives viable.

In this context, we propose the use of:

(1) DEA models to compute individual quotas, based on countries demographic and economic characteristics.

(2) ZSG-DEA models to support a basic framework for quota trade or emissions reallocation.

\subsection{Modelling}

The objective of this case study is to obtain a DEA frontier that represents a fair allocation of the carbon dioxide emission (undesirable output), contributing to the Kyoto Protocol and Carbon Market objectives, that is to stabilize greenhouse gas concentration in the atmosphere and/or carbon quotas trade that do not affect the global emission.

We considered that this maximum emissions concentration is the sum of the $2001 \mathrm{CO}_{2}$ emissions (most recent data available). By fair allocation, we mean that it is the one with which all countries become $100 \%$ DEA efficient, that is lie on the uniform DEA frontier.

The variables used are population (in millions of inhabitants), total energy consumption (in million BTU), gross domestic product-GDP (in US\$ billion) and $\mathrm{CO}_{2}$ emission (in ton ${ }^{3}$ of equivalent carbon).

A classical production model, such as the one by Kumar and Khanna (2002), would consider population and energy consumption as inputs, and GDP and $\mathrm{CO}_{2}$ emissions as outputs (desirable and undesirable, respectively). The model proposed here, as we are limited to the variables availability, intends not only to recognize one country's right to a certain emission level in relation to its economic production (expressed by GDP) or of its proxy (expressed by the energy consumption), but also of its population. The energy supply and, indirectly, the energy demand, condition a determined emission level, with a given generation technology. However, countries with a large population and moderate economic development, such as China and Russia, should not be penalized with a lower efficiency level in relation to countries with fewer inhabitants.

Thus, the model proposed in this paper suggests, for countries with the same $\mathrm{CO}_{2}$ emission level, that the one with the highest population, energy consumption and GDP will be more efficient. Alternatively, for the one with similar values for population, energy consumption and GDP, the most efficient is the one with the lowest emission levels. Thus, population, energy consumption, and GDP will be modelled as outputs, and the undesirable output $\mathrm{CO}_{2}$ emissions will be modelled as input. Population was considered as a nondiscretionary output.

The use of only $\mathrm{CO}_{2}$ emissions values as the undesirable output is justified by the fact that these emissions represent around $85 \%$ of greenhouse gas emissions. The data about $\mathrm{CO}_{2}$ emissions from EIA (2003) comprise the coal, petroleum, and natural gas consumption.

The DMUs to be considered are the signatory countries of the Kyoto Protocol, including the Annex I parties (developed countries responsible for $55 \%$ of global $\mathrm{CO}_{2}$ emissions). These data were obtained in UNFCCC (2003), concerning 83 countries. From these, 19 (two from Annex I-Liechtenstein and Monaco; the others are Antigua and Barbuda, Cook Islands, Cuba, Ecuador, Fiji, Mali, Marshall Islands, Micronesia, Niger, Niue, Papua New Guinea, Saint Lucia, Saint Vincent and the Grenadines, Samoa, Solomon Islands, Trinidad and Tobago, Tuvalu) were discarded, as there was no information regarding some of the variables (GDP data in major cases), which left us with a remaining set of 64 DMUs.

Discarding some DMUs could affect DEA results, since DEA efficiency analysis is always relative. However, the 19 missing countries represent only $0.43 \%$ of $\mathrm{CO}_{2}$ emissions in the group of 83 signatory countries, yielding a very low impact on the carbon quotas trading market. In addition, they represent only $1.55 \%$ of these 83 countries population and $0.22 \%$ of total energy consumption. The values of each variable for each DMU were obtained from EIA (2003). Population, energy consumption, GDP, and $\mathrm{CO}_{2}$ emissions data are from the year 2001. Thus, we want to verify which countries under these conditions are efficient, and what would be the fair allocation for the undesirable output $\mathrm{CO}_{2}$ emissions, that is how the emissions should be allocated among these countries (keeping the total unchanged), in order for all countries to be DEA efficient.

Among the above described approaches to treat undesirable outputs in DEA, the most common in the literature are 
the ones that models the undesirable output as an input and the other that uses the reciprocal of the undesirable output as an output. As already mentioned, the choice of one of these approaches is arbitrary; thus, we have decided to model the undesirable output as input, which best expresses the causal relationship, since the use of the reciprocal of the factor in the ZSG-DEA would imply constraining the sum to the reciprocal of the $\mathrm{CO}_{2}$ emissions to be a constant.

Färe and Grosskopf (2003) mention some drawbacks when treating undesirable outputs as inputs, though acknowledging that this approach is intuitively appealing. The first is the free disposability assumption, since in real case applications, unlimited increases in undesirable output (holding other inputs constant) are not technically possible. However, strong disposability is not an issue here, because we opted for an inputoriented approach and the input is bounded. Second, it is also worth noting that, when assessing power plants or energy sectors from a microeconomic perspective, the linkage between fuels, power and emissions should hold, as emphasized by Färe and Grosskopf (2005). The authors use an electric utility example to argue that fuels, power, and the undesirable factor $\mathrm{SO}_{2}$ are linked, so that 'to produce the same amount of power by reducing say coal by some amount by substituting additional amounts of the $\mathrm{SO}_{2}$ (holding all else constant) is not technically feasible, since the coal is the source of the $\mathrm{SO}_{2}$ '. However, our model deals with a normative country-level approach, where countries should find their way out through development of new technologies or quota trading (here imposed by the zero sum gains assumption), in order to achieve their 'best' target emission levels.

Besides choosing variables and DMUs, DEA modelling requires the model choice, either in relation to orientation or returns to scale. In this case study, we used DEA CCR model. Assuming CCR we are not treating benevolently neither technically efficient small, low-polluting countries, nor larger, big-polluting countries. Additionally, assuming constant returns to scale we avoid DMUs being efficient only by the absence of comparability, and the inefficient DMUs benchmarks are operating at the most productive scale size. As the restricted variable is modelled as input, DEA models were input-oriented. Thus, ZSG-DEA CCR input-oriented model, was applied to 64 DMUs, considering one input $\left(\mathrm{CO}_{2}\right.$ emissions) and three outputs (population, energy consumption, and GDP), as stated in Table 1.

Building the uniform DEA frontier requires cooperation among the inefficient DMUs. In our case, we preferred the direct procedure of searching for efficiency, that is, all DMUs that do not belong to the efficient frontier compose the cooperative group and search for efficiency directly in the piecewise linear frontier.

\subsection{Results}

Four DMUs were efficient in the CCR DEA model: Norway, Sweden, Switzerland, and Zambia. These efficient units contribute $0.73 \%$ to the total $\mathrm{CO}_{2}$ emissions. The average efficiencies is $49.5 \%$. Inefficient DMUs are in the cooperation group in the ZSG-DEA paradigm.

Complementary analysis can be made from Table 1 and from the complete results of the CCR model (weights, slacks, and benchmarks). The relationships between the input and each of the outputs can also bring interesting insights, that is these causal relationships are referred as the partial DEA frontiers.

Analyzing, for instance, the DMUs France and Ukraine, we see that, as Ukraine had low energy consumption and had $\mathrm{CO}_{2}$ emissions in the same order of France, the former is more efficient than Ukraine, considering that both assigned the biggest weight to the output, 'consumed energy'. Similarly, considering France and the United Kingdom: they have almost the same energy consumption, but the United Kingdom polluted more, which contributes to a smaller efficiency score in relation to France. It is possible to derive similar discussions concerning other DMUs.

Using the CCR efficiency scores, we determine new targets for the ZSG-DEA (Equation (2)), with the reallocation/ redistribution of the undesirable output $\mathrm{CO}_{2}$ emissions for the constant returns to scale case. A uniform CCR DEA frontier is built, where all DMUs are $100 \%$ efficient.

As already mentioned, after the emissions reallocation, all DMUs became efficient (Table 1). However, not all of them are Pareto efficient, as shown by the slack values. Some DMUs, Bulgaria, Canada and Russian Federation for example, have positive slacks in variable GDP (17\% of the total number of DMUs). There are no positive slacks relative to $\mathrm{CO}_{2}$ emissions, since the model imposes a constant sum of this input. Positive slacks mean zero multipliers and thus the possibility of changing the value of this variable without changing the value of another input or output. This is not the case of $\mathrm{CO}_{2}$ emissions, which assures that no increase without bounds can occur.

From a general viewpoint, ZSG-DEA results can be seen as a first approach for the quotas trade process. If some countries of the Kyoto Protocol Annex I aim to become efficient, they will increase their emissions values, at the expenses of the decrease of others (especially for the ones that are not Annex I parties).

ZSG-DEA CCR model benefits the countries that work at the optimal scale operation and punishes the ones that are not operating on the optimal scale. From this model, it can be seen that the United States must decrease its emissions and should search for partners that want or can reduce their emissions, in order to keep the global emission unchanged.

United Kingdom and Brazil, according to ZSG-DEA, may increase their $\mathrm{CO}_{2}$ emissions, and still remain efficient; therefore they can trade their excess quota. So, it is possible to propose a carbon quota trade process, as countries that can increase their emissions must negotiate the emissions reduction with the others. 
Table 1 Data, DEA CCR efficiency and reallocation promoted by ZSG-DEA CCR model

\begin{tabular}{|c|c|c|c|c|c|c|c|}
\hline Countries & $\begin{array}{c}\mathrm{CO}_{2} \\
\text { emissions }\end{array}$ & Population & $\begin{array}{c}\text { Energy } \\
\text { consumption }\end{array}$ & $G D P$ & $\begin{array}{l}\text { DEA CCR } \\
\text { efficiency }\end{array}$ & $\begin{array}{c}\mathrm{CO}_{2} \\
\text { emissions } \\
\text { after } \\
\text { reallocation }\end{array}$ & $\begin{array}{c}\text { DEA CCR } \\
\text { efficiency } \\
\text { after } \\
\text { reallocation }\end{array}$ \\
\hline Argentina* & 34.848 & 37.520 & 2664.873 & 280.049 & 0.483 & 41.193 & 1.000 \\
\hline Australia* & 99.029 & 19.490 & 4974.206 & 453.257 & 0.303 & 73.325 & 1.000 \\
\hline Austria* & 18.191 & 8.080 & 1419.417 & 268.651 & 0.617 & 27.443 & 1.000 \\
\hline Belgium* & 39.359 & 10.260 & 2773.546 & 321.571 & 0.451 & 43.440 & 1.000 \\
\hline Bolivia & 2.617 & 8.470 & 161.634 & 8.039 & 0.377 & 2.415 & 0.999 \\
\hline Brazil & 95.771 & 172.390 & 8782.125 & 771.454 & 0.559 & 131.045 & 0.999 \\
\hline Bulgaria* & 15.477 & 7.870 & 927.933 & 12.592 & 0.361 & 13.664 & 1.000 \\
\hline Canada ${ }^{*}$ & 156.189 & 31.080 & 12513.070 & 718.128 & 0.481 & 183.899 & 1.000 \\
\hline Chile & 14.754 & 15.400 & 1060.295 & 81.926 & 0.433 & 15.645 & 0.999 \\
\hline China & 831.736 & 1285.000 & 39665.259 & 1113.586 & 0.289 & 588.721 & 0.999 \\
\hline Costa Rica & 1.385 & 3.870 & 154.076 & 15.104 & 0.700 & 2.374 & 1.000 \\
\hline Croatia $^{*}$ & 5.687 & 4.660 & 429.164 & 23.352 & 0.454 & 6.325 & 1.000 \\
\hline Czech Republic ${ }^{*}$ & 29.006 & 10.290 & 1530.555 & 57.085 & 0.317 & 22.525 & 1.000 \\
\hline Denmark $^{*}$ & 16.242 & 5.330 & 895.227 & 207.444 & 0.485 & 19.268 & 1.000 \\
\hline Egypt & 34.290 & 67.890 & 2132.604 & 80.800 & 0.377 & 31.647 & 0.999 \\
\hline El Salvador & 1.525 & 6.400 & 114.658 & 11.242 & 0.495 & 1.847 & 1.000 \\
\hline Estonia $^{*}$ & 1.939 & 1.380 & 95.669 & 4.814 & 0.297 & 1.412 & 0.997 \\
\hline Finland* & 14.405 & 5.190 & 1326.014 & 173.566 & 0.613 & 21.596 & 1.000 \\
\hline France $^{*}$ & 108.126 & 59.190 & 10521.357 & 1812.350 & 0.734 & 194.203 & 1.000 \\
\hline Germany $^{*}$ & 223.240 & 82.360 & 14351.562 & 2701.903 & 0.507 & 276.752 & 1.000 \\
\hline Greece ${ }^{*}$ & 28.079 & 10.600 & 1393.198 & 144.773 & 0.310 & 21.301 & 1.000 \\
\hline Guatemala & 2.516 & 11.680 & 158.699 & 18.194 & 0.451 & 2.774 & 1.000 \\
\hline Honduras & 1.267 & 6.580 & 86.470 & 4.680 & 0.420 & 1.302 & 0.998 \\
\hline Indonesia & 87.128 & 214.840 & 4629.777 & 215.932 & 0.324 & 69.032 & 0.999 \\
\hline Ireland* & 11.148 & 3.840 & 609.289 & 112.914 & 0.428 & 11.667 & 1.000 \\
\hline Israel & 16.321 & 6.450 & 792.021 & 107.301 & 0.330 & 13.181 & 1.000 \\
\hline Italy $^{*}$ & 121.498 & 57.950 & 8110.681 & 1225.567 & 0.475 & 141.254 & 1.000 \\
\hline Japan* & 315.831 & 127.340 & 21921.986 & 5651.488 & 0.648 & 501.098 & 1.000 \\
\hline Kazakhstan & 33.366 & 14.830 & 1734.572 & 21.810 & 0.313 & 25.543 & 1.000 \\
\hline Latvia $^{*}$ & 2.654 & 2.360 & 205.871 & 6.026 & 0.467 & 3.035 & 0.997 \\
\hline Lithuania $^{*}$ & 4.330 & 3.490 & 329.191 & 7.513 & 0.458 & 4.851 & 0.999 \\
\hline Luxembourg ${ }^{*}$ & 2.467 & 0.440 & 203.096 & 25.466 & 0.539 & 3.253 & 1.000 \\
\hline Malaysia & 36.151 & 23.630 & 2274.952 & 112.213 & 0.379 & 33.521 & 1.000 \\
\hline Maldives & 0.133 & 0.280 & 6.766 & 0.543 & 0.312 & 0.102 & 1.000 \\
\hline Malta & 1.072 & 0.390 & 51.413 & 3.989 & 0.289 & 0.757 & 0.990 \\
\hline Mexico & 96.048 & 101.750 & 6003.999 & 372.405 & 0.377 & 88.661 & 0.999 \\
\hline Netherlands ${ }^{*}$ & 67.519 & 16.040 & 4231.063 & 502.581 & 0.404 & 66.723 & 1.000 \\
\hline New Zealand* & 9.612 & 3.850 & 844.122 & 70.975 & 0.528 & 12.414 & 0.999 \\
\hline Nicaragua & 1.018 & 5.210 & 58.122 & 2.384 & 0.353 & 0.879 & 0.995 \\
\hline Norway* & 11.448 & 4.510 & 1906.093 & 172.911 & 1.000 & 28.012 & 1.000 \\
\hline Panama & 2.257 & 2.860 & 138.456 & 9.395 & 0.371 & 2.047 & 0.999 \\
\hline Paraguay & 0.958 & 5.640 & 110.929 & 9.593 & 0.732 & 1.716 & 0.998 \\
\hline Peru & 7.185 & 26.350 & 550.334 & 60.888 & 0.517 & 9.095 & 0.998 \\
\hline Philippines & 18.624 & 77.130 & 1254.272 & 91.235 & 0.417 & 19.022 & 0.998 \\
\hline Poland* & 78.608 & 38.640 & 3536.036 & 165.274 & 0.271 & 52.113 & 1.000 \\
\hline Portugal ${ }^{*}$ & 16.250 & 10.020 & 1088.212 & 131.884 & 0.437 & 17.372 & 1.000 \\
\hline Republic of Korea & 120.800 & 47.340 & 8058.116 & 639.239 & 0.401 & 118.559 & 1.000 \\
\hline Romania $^{*}$ & 25.970 & 22.410 & 1637.662 & 34.918 & 0.380 & 24.157 & 1.000 \\
\hline Russian Federation ${ }^{*}$ & 440.260 & 144.400 & 28197.166 & 366.904 & 0.385 & 414.763 & 1.000 \\
\hline Seychelles & 0.165 & 0.080 & 8.450 & 0.620 & 0.308 & 0.124 & 1.000 \\
\hline Slovakia* & 10.825 & 5.400 & 832.038 & 23.806 & 0.462 & 12.244 & 1.000 \\
\hline Slovenia ${ }^{*}$ & 4.060 & 1.990 & 305.558 & 23.864 & 0.453 & 4.497 & 0.999 \\
\hline Spain ${ }^{*}$ & 82.722 & 40.270 & 5699.314 & 723.243 & 0.455 & 92.157 & 1.000 \\
\hline Sweden ${ }^{*}$ & 14.584 & 8.830 & 2221.195 & 281.291 & 1.000 & 35.686 & 1.000 \\
\hline Switzerland* & 12.266 & 7.230 & 1304.669 & 340.276 & 1.000 & 30.014 & 1.000 \\
\hline
\end{tabular}


Table 1 Continued

\begin{tabular}{|c|c|c|c|c|c|c|c|}
\hline Countries & $\begin{array}{c}\mathrm{CO}_{2} \\
\text { emissions }\end{array}$ & Population & $\begin{array}{c}\text { Energy } \\
\text { consumption }\end{array}$ & $G D P$ & $\begin{array}{l}\text { DEA CCR } \\
\text { efficiency }\end{array}$ & $\begin{array}{c}\mathrm{CO}_{2} \\
\text { emissions } \\
\text { after } \\
\text { reallocation }\end{array}$ & $\begin{array}{c}\text { DEA CCR } \\
\text { efficiency } \\
\text { after } \\
\text { reallocation }\end{array}$ \\
\hline Thailand & 48.494 & 62.910 & 2903.942 & 174.973 & 0.362 & 42.949 & 0.999 \\
\hline Turkmenistan & 7.677 & 4.880 & 477.263 & 6.965 & 0.374 & 7.032 & 1.000 \\
\hline Ukraine* & 96.575 & 49.110 & 6076.237 & 36.431 & 0.379 & 89.465 & 1.000 \\
\hline United Kingdom ${ }^{*}$ & 154.326 & 59.540 & 9810.060 & 1334.922 & 0.432 & 162.967 & 1.000 \\
\hline United States* & 1565.311 & 283.974 & 97049.875 & 9039.464 & 0.375 & 1436.072 & 1.000 \\
\hline Uruguay & 1.690 & 3.360 & 157.357 & 20.794 & 0.642 & 2.652 & 0.999 \\
\hline Uzbekstan & 30.160 & 25.560 & 2075.012 & 12.802 & 0.415 & 30.595 & 1.000 \\
\hline Vietnam & 12.561 & 79.180 & 760.127 & 30.994 & 0.376 & 11.548 & 0.997 \\
\hline Zambia & 0.558 & 10.650 & 89.457 & 4.082 & 1.000 & 1.366 & 1.000 \\
\hline
\end{tabular}

Total.

*Annex I parties.

We can also see from the results of ZSG-DEA model that the emissions are allowed to increase in more than half of the DMUs sample.

\section{Conclusions}

DEA models, when applied to the carbon quota trade, one of the Kyoto Protocol objectives, introduce important characteristics as they propose conceptual models that surpass the simple maintenance of the status quo.

ZSG-DEA models bring a theoretical innovation very appropriate to the concept of the flexible mechanisms: a basic scenario for emission reallocation, ensuring global efficiency. Modelling undesirable outputs with ZSG-DEA models fills a gap in the DEA literature regarding the allowance for reallocating/redistributing these amounts among the evaluated units, in order to build an optimal, or fair allocation. These models are the first attempt at building the uniform DEA frontier, based on the $\mathrm{CO}_{2}$ emissions reallocation. Advanced models can be developed, for example, as ZSG-DEA models that assign weight restrictions to outputs are concerned. Lins et al (2003) provided some initial steps in this direction.

The uniform DEA frontier shows the possibilities of ZSGDEA models in the decision-aid context, particularly in devising development plans for the evaluated units. Thus, these case study results, especially regarding the $\mathrm{CO}_{2}$ emission quotas trade, may settle a reference point for bargaining, based on technical criteria and aiming at a fair allocation of responsibilities, besides commercial or political aspects.

Yet we could suggest two future improvements regarding application of undesirable outputs DEA models. The first one is to consider the other greenhouse gases as undesirable outputs. In this case, ZSG-DEA models may incorporate weight restrictions, as each pollutant has a different importance for the greenhouse effect. The second improvement consists of restricting the weight ranges assigned to the variables, considered here as outputs.
Acknowledgements - We thank the anonymous referee for his helpful comments.

\section{References}

Ali AI and Seiford LM (1990). Translation invariance in data envelopment analysis. Opns Res Lett 9: 403-405.

Avellar JVG, Milioni AZ and Rabello TN (2006). Spherical frontier DEA model based on a constant sum of inputs. J Opl Res Soc, doi: $10.1057 /$ palgrave.jors.2602260.

Banker RD, Charnes A and Cooper WW (1984). Some models for estimating technical scale inefficiencies in data envelopment analysis. Mngt Sci 30: 1078-1092.

Charnes A, Cooper WW, Golany B, Seiford LM and Stutz J (1985). Foundations of data envelopment analysis for Pareto-Koopmans efficient empirical production functions. J Econom 30: 91-127.

Charnes A, Cooper WW and Rhodes E (1978). Measuring the efficiency of decision-making units. Eur J Opl Res 2: 429-444.

Cooper WW, Seiford LM and Tone K (2000). Data Envelopment Analysis: A Comprehensive Text with Models, Applications, References and DEA-Solver Software. Kluwer Academic Publishers: Boston.

Dyckhoff H and Allen K (2001). Measuring ecological efficiency with data envelopment analysis (DEA). Eur J Opl Res 132: 312-325.

EIA (2003). US Energy Information Administration Homepage. http://www.eia.doe.gov/, accessed 6 August 2006.

Färe R and Grosskopf S (1995). Environmental decision models with joint outputs. Economics Working Paper Archive, Economic Department, Washington University.

Färe R and Grosskopf S (2001). Optimization models applied to productivity and the environment. XXXIII Simpósio Brasileiro de Pesquisa Operacional, Campos do Jordão, Brazil.

Färe R and Grosskopf S (2003). Nonparametric productivity analysis with undesirable outputs: Comment. Am J Agri Econom 85: $1070-1074$.

Färe R and Grosskopf S (2004). Modelling undesirable factors in efficiency evaluation: Comment. Eur J Opl Res 157: 242-245.

Färe R and Grosskopf S (2005). New Directions: Efficiency and Productivity. Kluwer Academic Publishers: Boston.

Färe R, Grosskopf S, Lovell CAK and Pasurka C (1989). Multilateral productivity comparisons when some outputs are undesirable: A nonparametric approach. Rev Econom Statist 71: 90-98.

Färe R, Grosskopf S and Tyteca D (1996). An activity analysis model of the environmental performance of firms-application to fossilfuel-fired electric utilities. Ecolog Econom 18: 161-175. 
Färe R, Grosskopf S and Zaim O (2000). An index number approach to measuring environmental performance: An environmental Kuznets curve for OECD countries. New Zealand Econometrics Study Group Meeting, University of Canterbury.

Golany B and Roll Y (1989). An application procedure for DEA Omega-Int J Mngt Sci 17: 237-250.

Gomes EG (2003). Modelos de Análise de Envoltória de Dados com Ganhos de Soma Zero (Zero Sum Gains Data Envelopment Analysis Models). Doctoral thesis, COPPE/Federal University of Rio de Janeiro, Rio de Janeiro, Brazil.

Gomes EG, Soares de Mello JCCB and Lins MPE (2003). Busca sequiencial de alvos intermediários em modelos DEA com soma de outputs constante (Step by step target search in Zero Sum Gains DEA models). Investigação Operacional 23: 1-16.

Gomes EG, Soares de Mello JCCB and Lins MPE (2005). Uniformizaç ao da fronteira eficiente em modelos de Análise de Envoltória de Dados com Ganhos de Soma Zero e Retornos Constantes de Escala (Uniform efficient frontier in Zero Sum Gains DEA CCR models). Pesquisa Operacional 25: 261-277.

Hailu A and Veeman TS (2001). Non-parametric productivity analysis with undesirable outputs: An application to the Canadian pulp and paper industry. Am J Agri Econom 83: 605-616.

Korhonen P and Luptacik M (2003). Eco-efficiency analysis of power plants: An extension of data envelopment analysis. Euro J Opl Res 154: $437-446$.

Kumar S and Khanna M (2002). Productivity growth and $\mathrm{CO}_{2}$ abatement: A cross-country analysis using the distance function approach. International Conference on Climate Change and Environmental Policy, University of Illinois, http://www.ace uiuc.edu/pERE/conference/papers.

Lins MPE, Gomes EG, Soares de Mello JCCB and Soares de Mello AJR (2003). Olympic ranking based on a zero sum gains DEA model. Eur J Opl Res 148: 312-322.

Lovell CAK, Pastor JT and Turner JA (1995). Measuring macroeconomic performance in the OECD: A comparison of European and non-European countries. Eur J Opl Res 87: 507-518.

Lozano SN and Villa G (2004). Centralized resource allocation using data envelopment analysis. J Prod Anal 22: 143-161.

Murtough G, Appels D, Matysek A and Lovell CAK (2002). Why greenhouse gas emissions matter when estimating productivity growth: An application to Australian electricity generation. Proceedings of the 2nd World Congress of Environmental and Resource Economists, Monterey, California.

Osborne MJ and Rubinstein AA (1999). A Course in Game Theory. The MIT Press: Boston.

Rheinhard S, Lovell CAK and Thijssen G (1999). Econometric estimation of technical and environmental efficiency: An application to Dutch dairy farms. Am J Agri Econom 81: 44-60.

Rheinhard S, Lovell CAK and Thijssen G (2000). Environmental efficiency with multiple environmentally detrimental variables estimated with SFA and DEA. Eur J Opl Res 121: 287-303.

Sachs I (2000). Understanding Development: People, Markets \& the State in Mixed Economies. Oxford University Press: Oxford.

Scheel H (2001). Undesirable outputs in efficiency evaluations. Eur J Opl Res 132: 400-410.

Seiford LM and Zhu J (2002). Modelling undesirable outputs in efficiency evaluation. Eur J Opl Res 142: 16-20.

Sun S (2002). Measuring the relative efficiency of police precincts using data envelopment analysis. Socio-Econom Plan Sci 36: $51-71$.

Thanassoulis E (1995). Assessing police forces in England and Wales using data envelopment analysis. Eur J Opl Res 87: 641-657.

Tyteca D (1996). On the measurement of the environmental performance of firms-A literature review and a productivity efficiency perspective. J Environ Mngt 46: 281-308.

UNFCCC (2003). The convention and the Kyoto protocol. United Nations Framework Convention on Climate Change. http://unfccc.int/resource/convkp.html, accessed 8 August 2006.

Yaisawarng S and Klein JD (1994). The effects of sulfur dioxide controls on productivity change in the US electric power industry. Rev Econom Statist 76: 447-460.

Zofio JL and Prieto AM (2001). Environmental efficiency and regulatory standards: The case of $\mathrm{CO}_{2}$ emissions from OECD industries. Resource Energy Econom 23: 63-83.

Received October 2005; accepted October 2006 after two revisions 